\title{
RESPONSE OF SUGARCANE ON AGRO CLIMATIC CONDITIONS AND DROUGHT WITH MITIGATION STRATEGIES
}

\author{
Zulfqar Waseem Malik and Zia ul Hussnain \\ Fatima Sugar Mills, Muzaffargarh \\ Corresponding Author: zia.hussnain@fatima-group.com
}

\section{ABSTRACT}

Climatic changes are the main concerns of varying crop yields nowadays. The world has reached where it will start a journey towards deterioration. Sustainable production will ensure food security in days to come. Sugarcane is considered a major crop for sugar as well as bio-fuel production in the world. Environmental changes have severely affected the cane production worldwide especially in the developing countries because of relatively low adaptive capacity, high vulnerability to natural hazards, poor forecasting systems and mitigating strategies. The changing rainfall patterns (Monsoon season) during July to September due to climate change may result in water stress induced by drought although harvesting efficiency is expected to increase. These studies also expound on the mitigation and adaptation strategies that can be employed in the sugarcane industry as a way of reducing losses in sugarcane production. This will also help to know how cane production is affected due to extreme environmental changes in Pakistan.

\section{INTRODUCTION}

A combination of long-term change in the weather patterns worldwide (i.e., global climate change), caused by natural processes and anthropogenic factors, may result in major environmental issues that have affected and will continuously affect agriculture.

Sugarcane is an important cash crop of Pakistan. It is mainly grown for sugar and sugary production. Climate variability has a major impact not only on sugar production but also on the national economy in Pakistan. High temperatures accompanied by drought stress have been two of the major issues influencing agricultural production and economic impacts in many regions of the world. Therefore, it is essential to understand the impact of major changes in climate patterns that affect sugarcane and sugar industry. Climate variability and climate change are projected to result in changes in sea levels, rainfall pattern, and the frequency of extreme high and low temperature events, floods, droughts, and other abiotic stresses (Dhillon and Wuehlisch, 2013). The challenges faced by the agricultural sector regarding the sugarcane crop under the climate change scenarios are discussed below.

Climatic requirements for sugarcane cultivation

Sugarcane is a tropical plant and it can also grow in sub- tropics with cooler and dried climatic conditions helpful for the sugar accumulation in stalk. Since last eighty years, the varietal importance of sugarcane cultivation has supported to tropic and subtropic cultivars to produce high stock yield among with sucrose percentage of very wider adaptation. Under warm humid conditions, it continues its growth unless terminated by flowering. A mean temperature of $28-30^{\circ} \mathrm{C}$ is best suited for the growth of sugarcane.

Lower temperature reduces tillering. Temperature above $50^{\circ} \mathrm{C}$ ceases its growth and below $20^{\circ} \mathrm{C}$ slows its growth. The areas with a minimum temperature $<5^{\circ} \mathrm{C}$ are not suitable for sugarcane cultivation. 
The crop does well in tropical regions receiving an annual rainfall of 750-1200 mm (Kanchan, 2009). A relative humidity of $70-85 \%$ during growth and $55-75 \%$ during ripening phase is ideal while $<50 \%$ during growing season is not suitable for sugarcane cultivation. Rainfall deficiency produces a fibrous cane, whereas too heavy rainfall reduces sugar content. In many areas, mostly the water is supplemented by the canals. Much sunshine is required, particularly at the end of the growing season, to produce cane with high sugar content.

Cardozo and Sentelhas (2013) stated that sugarcane ripening is the process of sucrose accumulation in stalks, which is heavily influenced by several factors, mainly by climatic conditions such as air temperature and water deficits. Sugarcane ripening depends on a complex combination of climate variables, the genetic potential of cultivars and crop management. Soil moisture and air temperature are the primary variables involved in sugarcane ripening, and their combination stimulates the intensity of the process

Shakoor et, al., (2011) found significant negative impact of temperature-rise and found the positive impact of rainfall on agriculture production including the sugarcane crop. Studies concluded that the negative impact of temperature is greater than the positive impact of rainfall for the sugarcane crop in Pakistan.

\section{Impact of climate on yield and sucrose}

The sugarcane productivity and juice quality are the two major factors much concerned for sugar industry but profoundly influenced by weather conditions prevailing during the various cropgrowth periods. Increases in atmospheric $\mathrm{CO}_{2}$ and air temperature can be beneficial for sugarcane crop in some places (Tao et. al., 2006). Sugar recovery is maximum when the weather is dry with low humidity, bright sunshine hours, cooler nights with wide diurnal variations and very little rainfall during ripening period. These conditions favor high sugar accumulation. Gawander, 2007 stated that the sugarcane and sugar yields have fluctuated with extreme climate events of drought and tropical cyclones. Drought in early and mid-growth stages mainly reduces sucrose contents and cane yield. Moderate drought in late growth stage can improve sucrose content in stalks. Extreme temperature reduces cane production because of reduced maturity due to long growing season, reduced tillering due to drought and high temperatures and favouring weather for the attack of pests and diseases will also cause drop in yield as well as the sucrose content of sugarcane crop.

Loss in sugarcane yield with a change of 1-degree Celsius

\begin{tabular}{|c|c|c|c|}
\hline Year & \multicolumn{3}{|c|}{ Mounds per Acre } \\
\hline & Production & Loss & Cumulative \\
\hline 2016 & 904.35 & 4.89 & 4.89 \\
\hline 2017 & 899.2 & 5.144 & 9.92 \\
\hline 2018 & 893.81 & 5.39 & 15.21 \\
\hline 2019 & 888.16 & 5.64 & 20.81 \\
\hline 2020 & 882.26 & 5.89 & 32.34 \\
\hline 2021 & 876.11 & 6.14 & 38.64 \\
\hline 2022 & 869.72 & 6.39 & 45.12 \\
\hline 2023 & 863.06 & 6.65 & 52.64 \\
\hline 2024 & 856.16 & 6.9 & 59.73 \\
\hline 2025 & 849.01 & 7.15 & 6.09 \\
\hline \multicolumn{4}{|l|}{} \\
\hline
\end{tabular}

Reference: Rehan et.al, 2012 
Loss in sugarcane yield with a change of 2-degree Celsius

\begin{tabular}{|c|c|c|c|}
\hline Year & \multicolumn{3}{|c|}{ Mounds per Acre } \\
\hline & Production & Loss & Cumulative \\
\hline 2016 & 856.75 & 13.55 & 13.55 \\
\hline 2017 & 841.61 & 14.55 & 28.1 \\
\hline 2018 & 826.04 & 15.56 & 43.58 \\
\hline 2019 & 809.48 & 16.56 & 59.65 \\
\hline 2020 & 791.91 & 17.57 & 78.97 \\
\hline 2021 & 773.33 & 18.57 & 95.99 \\
\hline 2022 & 753.75 & 19.57 & 115.43 \\
\hline 2023 & 733.17 & 20.58 & 135.84 \\
\hline 2024 & 711.58 & 21.58 & 156.74 \\
\hline 2025 & 688.99 & 22.59 & 179.15 \\
\hline \multicolumn{3}{|c|}{ Percent Loss } \\
\hline
\end{tabular}

Reference: Rehan et.al, 2012

Impact of ater ogging on ugarcane

Waterlogging in Pakistan is a major problem to the sugar industry and is also a widespread phenomenon that drastically reduces the growth of sugarcane crop.

Rise in temperature promotes the melting of glaciers that adds excess water in the rivers. Area surrounding the Indus River is mostly affected with prolonged water logging which not only affects the yield but also the sucrose content of the cane crop. It is one of the serious environmental constrain for optimum growth and yield of sugarcane crop for the area. Higher rate of stalk mortality, low relative growth rate and reduced cane yield are major effects of waterlogging.

One way of overcoming the reduced yield is to develop sugarcane cultivars that are more resistant to waterlogging. It also causes $18-64 \%$ reduction in cane yield, depending on duration of water logging, plant growth stage and cultivars.

Although, IISR (2016) proved that some sugarcane varieties can withstand both moisture stress and waterlogging, hence, capable of providing a boost to sugar recovery and cane production.

\section{Sugarcane average yield in comparison to waterlogging at fatima sugar mills limited area}

\begin{tabular}{|c|c|c|}
\hline Water-table Depth & $\begin{array}{c}\text { Yield } \\
(\mathrm{Kg} / \mathrm{ha})\end{array}$ & $\begin{array}{c}\text { Average Yield } \\
\text { (Mounds/acre) }\end{array}$ \\
\hline$<0.5 \mathrm{~m}$ & 30984 & 313 \\
\hline $0.5-1.0 \mathrm{~m}$ & 39643 & 401 \\
\hline $1.0-2.0 \mathrm{~m}$ & 59478 & 602 \\
\hline $2.0-3.0 \mathrm{~m}$ & 52762 & 537 \\
\hline
\end{tabular}




\section{Interaction of major factors influencing yield}

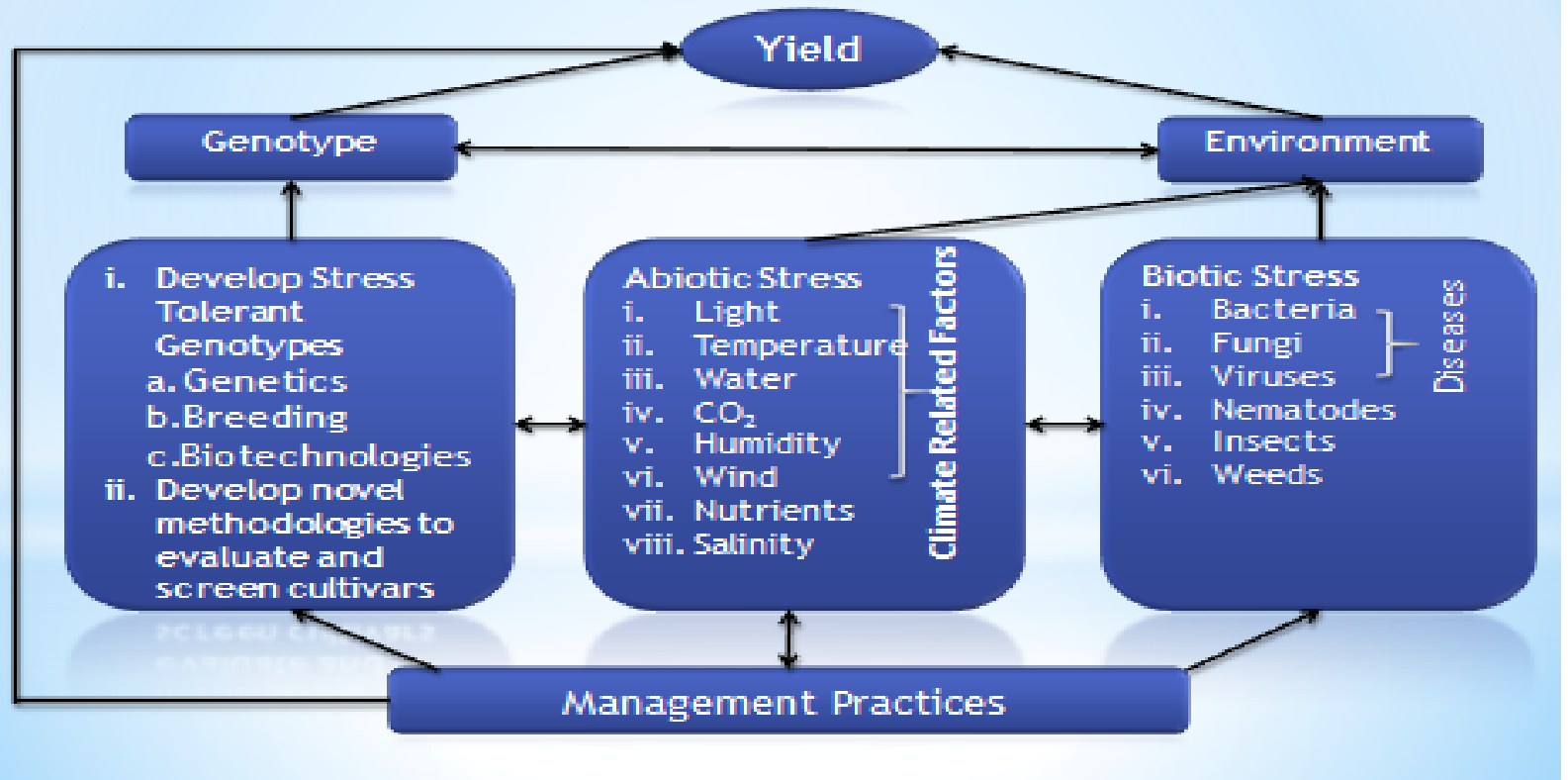

\section{Effects of climate change on insects}

\section{Rising temperature}

Insects are particularly sensitive to temperature because they are stenotherm (cold-blooded). In general, insects respond to higher temperature with increased rates of development and with less time between generations. Warmer winters reduce winter kill and consequently induce increased insect populations in the subsequent growing season. Climate change resulting in increased temperature could impact crop pest insect population in several complex ways. Higher temperature may be more favorable for the proliferation of insect pests (longer growing seasons, higher possibility to survive during winter). It can also potentially affect the insect survival, development, geographic range and population size.
Temperature can influence insect physiology and development directly or indirectly through the physiology or existence of hosts (Kambrekar, 2015). Depending on the development strategy of an insect species, temperature can exert different effects such as extends the growing season of insect, greater numbers of generation, faster resistance to insecticides, earlier migration and maturation and greater winter survival and less mortality (Stern and Britain, 2007).

\section{Impact of high $\mathrm{CO}_{2}$ on insect-plant interaction}

The biological effects of global climatic change are among the most important issues in ecological research. Several studies have shown that insect herbivores consistently respond to changes in plant quality induced by enriched $\mathrm{CO}_{2}$ environments by consuming more foliage (Marks and Lincoln 1996 and Osbrink et, al., 1987) and perhaps with reduced growth (Lincoln et. Al., 1986, and Fajer 1989).

In most of the studies on impact of elevated $\mathrm{CO}_{2}$ on insect-plant interactions, the insects in ambient conditions were fed with detached leaves of host plants grown under elevated $\mathrm{CO}_{2}$. However, there are a few studies in which both insects and host plants were exposed to elevated $\mathrm{CO}_{2}$ but these studies couldn't pinpoint the direct effects of elevated $\mathrm{CO}_{2}$ on insects. Hence there is a need to further examine how insects get affected when exposed directly to elevated $\mathrm{CO}_{2}$ concentrations. However, herbivores respond to increased levels of $\mathrm{CO}_{2}$ by increasing their food consumption, prolonging development time, and 
reducing their growth rates and food conversion efficiency (Watt et al., 1995). In general, host plant quality declines in elevated $\mathrm{CO}_{2}$ with leaf nitrogen decreasing and phenolic increasing. Changes in nitrogen content are correlated with changes in food consumption and changes in phenolic with changes in food digestibility. Studies revealed that increased Carbon : Nitrogen in plants makes poorer forage for insects, plant defenses shift from nitrogen to carbon based, produce fewer toxins, phenols and tougher leaves, less nutrient uptake due to immobilization (Coviella \& Trumble, 1999).

\section{Environmental affecting development}

The classic disease triangle (Host, Pathogen, and environment) recognizes the role of climate in plant diseases as no virulent pathogen can induce disease on a highly susceptible host if climatic conditions are not favorable. Climate influences all stages of host and pathogen life cycles as well as development of disease. Disease severity over a period can fluctuate according to climatic variation.

Higher temperature and humidity if supported by greater precipitation result in the spread of plant diseases, as wet vegetation promotes the germination of spores and the proliferation of fungi and bacteria, and influences the life cycle of soil nematodes.
In regions that suffer aridity, however, disease infestation lessens, although some diseases (such as the powdery mildews) thrive in hot, dry conditions, as long as there is dew formation at night. Most crop diseases have greater potential to reach severe levels under warmer conditions. Fungal and bacterial pathogens are also likely to increase in severity in areas where precipitation increases. In addition, increase in population levels of disease vectors could lead to increased epidemics of the disease they carry.

\section{Temperature}

In most locations, temperature changes had significant effects on disease development. However, these effects varied between different agro-ecological zones. Most crop diseases have greater potential to reach severe levels under warmer conditions. Change in temperature will directly influence infection, reproduction, dispersal, and survival between seasons and other critical stages in the life cycle of a pathogen. Each pathogen has an optimum temperature for growth, different growth stages of the pathogens have slightly different optimum temperatures e.g. incidence of sugarcane smut disease increases due to high temp and dry weather promotes the symptoms of ratoon stunting disease in sugarcane crop (Chandiposha, 2013)

\section{Relative humidity}

Some pathogens are more likely to infect plants with increased moisture. Other pathogens like the powdery mildew species tend to thrive in conditions with lower (but not low) moisture. Bacteria are spread to their host plants mainly by water, usually in the form of rain splash and insects. In humid, wet conditions, infected plant tissues can exude masses of bacteria that are spread from host to host by rain splash and insects. Therefore, the warmer drier summers expected with climate change should limit bacterial diseases. Precipitation following fungicide application may improve its distribution (Schepers, 1996) but an increase in rainfall intensity can deplete fungicide residue on the foliage. Forecast models for these diseases are based on leaf wetness, relative humidity and precipitation measurements.

Relative humidity is very critical in fungal spore germination and the development of sugarcane rots. High humidity favors development of the leaf and stem diseases in majority caused by fungi and bacteria. Moisture is generally needed for pathogen spore germination, the multiplication and the initiation of infection Reference: Chandiposha, 2013

\section{Soil moisture}

Most of the sugarcane diseases spread through soil that acts as a primary transmission vector along with diseased setts, while the source for secondary 
transmission is the air and rain splash.

- Optimum soil moisture may be a limiting factor in the development of certain root rot diseases.

- Low soil moisture for long time is favorable for disease development.

- High soil-moisture levels favour development of destructive mold fungi such as the species of Pythium and Phytophthora.

Reference: Chandiposha, 2013

\section{Things we need to do!}

Assessing agriculture and crop production systems as well as climatic change and its negative impact on many economic, environmental and social issues have to be thoroughly considered.

1. Balance short-term and long-term goals (Germination, Fertilization \& disease control).

2. Increase productivity, profitability and sustainability.

3. Introduce new technologies and transfer them to growers.

\section{Mitigation Strategies}

Reliable predictions of climate change impacts on water use, irrigation requirements and yields of irrigated sugarcane are necessary to plan adaptation strategies. Although, climate change increases the frequency and intensity of extreme weather events also the uncertainty and vulnerability of adverse effects on agriculture. Much more efforts are needed to focus on increasing yield and improving profits under the current conditions. In future, due to change in climatic conditions, sugarcane yield relies on following parameters planting drought tolerant varieties, investing irrigation infrastructure, improving irrigation efficiency \& drainage system, improving cultural and management practices and development of the stress tolerant \& highyielding sugarcane cultivars.

Using technologies of molecular biology and gene transformation to develop genetically modified (GM) sugarcane varieties having Herbicide resistance. Drought tolerance. High sugar content. Disease resistance.

\section{Future prospects to overcome the climate} change for sugarcane crop In addition to development of disease resistant cultivars by breeding and variety development programs, integration of the best management practices (BMPs) for pest control and for increases in water and nutrient use efficiencies is also crucial for the climate change adaptation and sugarcane yield improvement. Although, existing adaptation strategies may offset many problems related to negative impact of climate change but not all in the future. These effects may be worsened after 2050, especially if greenhouse gas emissions still remain high. Therefore, agricultural scientists and decision makers need to work closely using multidisciplinary approaches.

- Development of new sugarcane cultivars consistently using breeding and molecular biology.

- Refining best management practices

- Improving new technology transfer by increasing productivity and profitability.

- Protection of the natural resource (especially water and soil) for sustainability

- Expanding use of sugarcane products for sugar, ethanol and other co-products. 


\section{REFERENCES}

ADB. 2009. Building climate resilience in the agriculture sector in Asia and in the Pacific. Asian Development Bank, Annual Development Report, p. -9.

Cardozo N. P. and Sentelhas P. C. 2013. Climatic effects on sugarcane ripening under the influence of cultivars and crop age. Scientia Agricola 70(6):449-456.

Carlose E. Coviella and John T. Trumble. 1999. Effect of elevated atmospheric carbon dioxide on insect-plant interaction. Conservation Biology, 13(4) 700-712.

F. Tao, M. Yokozawa, Y. Xu, Y. Hayashi, and Z. Zhang, "Climate changes and trends in phenology and yields of field crops in China, 1981-2000," Agricultural and Forest Meteorology, vol. 138, no. 1-4, pp. 82-92, 2006.

Fajer E.D., Bowers M.D., Bazzaz F. A. 1989. The effects of enriched carbon dioxide atmospheres on plant-insect herbivore interactions. Science. 243, 1198-1200.

FSRDC. 2014-15. Annual Research Report of the Fatima Sugar Research \& Development Farms.

J. Gawander, "Impact of climate change on sugar-cane production in Fiji," WMO Bulletin, vol. 56, pp. 34-39, 2007.

Kambrekar D. N. 2015. Impact of rising temperature on pests. Regional Agricultural Research Station, PB. No. 18, Vijayapur-586 101, Karnataka

Kanchan N. 2009. Weed Infestation in sugarcane.(C.F.ONLINE) www.atsdr.cdc.gov.

Lincoln D.E., Couvet D., Sionit N. 1986. Response of an insect herbivore to host plants grown in carbon dioxide $\square$ enriched atmospheres. Oecologia. 69, 556-560.

M. Chandiposha, "Potential impact of climate change in sugarcane and mitigation strategies in Zimbabwe," African Journal of Agricultural Research, vol. 8, pp. 2814-2818, 2013.

Marks S, Lincoln DE. 1996. Antiherbivore defence mutualism under elevated carbon dioxide levels: a fungal endophyte and grass. Environmental Entomology. 25, 618-623.

Mendelsohn, R., W. Nordhaus and D. Shaw. 1994. The impact of global warming on agriculture: A Ricardian analysis. The American Economic Review 84:753-771.

Osbrink WLA, Trumble JT, Wagner RE. 1987. Host suitability of Phaseolus lunatus for Trichoplusiani (Lepidoptera: Noctuidae) in controlled carbon dioxide atmospheres. Environmental Entomology. 16, 639-644.

R. S. Dhillon and G. von Wuehlisch, "Mitigation of global warming through renewable biomass," Biomass and Bioenergy, vol. 48, pp. 75-89, 2013.

Rehana S. samad G, Nasir M. and Jalil H.H. The Impact of Climate Change on Major Agricultural Crops: Evidence from Punjab, Pakistan. The Pakistan Development Review 51(4).

Schepers, H.T.A.M. 1996. Effect of rain on the efficacy of fungicide deposits on potato against Phytophthora infestans. Potato Research, 39: 541-50

Shakoor Usman, Abdul Saboor, Ikram Ali, and A.Q. Mohsin (2011). Impact of Climate Change on Agriculture: Empirical Evidence from Arid Region. Pak. J. Agri. Sci. 48(4), 327-333.

Shakoor, Usman, Abdul Saboor, Ikram Ali, and A. Q. Mohsin (2011) Impact of Climate Change on Agriculture: Empirical Evidence from Arid Region. Pak. J. Agri. Sci 48:4, 327-333.

Stern, N. H., and Great Britain. 2007. The economics of climate change: The Stern review. Cambridge, UK: Cambridge University Press.

Watt, A.D., R. Harrington, and E. Stork. 1995. Insects in a Changing Environment. Symp. Royal Ent. Soc. Acad. Press, London, pp. 198-217. 